Commentary

\title{
A Critical Perspective on Ageism and Modernization Theory
}

\author{
Wouter De Tavernier ${ }^{1, *}$, Laura Naegele ${ }^{2}$ and Moritz Hess ${ }^{3}$ \\ ${ }^{1}$ Center for Social and Cultural Psychology, KU Leuven, 3000 Leuven, Belgium; E-Mail: wouter.detavernier@kuleuven.be \\ ${ }^{2}$ Institute of Gerontology, Department of Ageing and Work, University of Vechta, 49364 Vechta, Germany; \\ E-Mail: laura.naegele@uni-vechta.de \\ ${ }^{3}$ Department of Dynamics of Inequality in Welfare Societies, University of Bremen, 28359 Bremen, Germany; \\ E-Mail:mhess@uni-bremen.de \\ * Corresponding author
}

Submitted: 18 July 2018 | Accepted: 18 July 2019 | Published: 29 July 2019

\begin{abstract}
Modernization theory has often been used to explain country differences in levels of ageism. The commentary at hand questions its usefulness in the analysis of ageism today for two reasons. First, modernization theory was developed to discuss social status of older people, not ageism. Second, social policies and management practices that emerged with industrialization are being rolled back over the last decades. We therefore argue for the reconsideration of the relationship between modernization and ageism and to re-assess it in order to better explain country differences in ageism in the 21st century.
\end{abstract}

\section{Keywords}

age discrimination; ageism; older population; modernization theory; social status; stereotypes

\section{Issue}

This commentary is part of the issue "Old-Age Exclusion", edited by Wouter De Tavernier (KU Leuven, Belgium) and Marja Aartsen (OsloMet-Oslo Metropolitan University, Norway).

(C) 2019 by the authors; licensee Cogitatio (Lisbon, Portugal). This article is licensed under a Creative Commons Attribution 4.0 International License (CC BY).

\section{Introduction}

Modernization theory is one of the main theories explaining ageism at the macro-level. The essence of the argument is that ageism increases as societies modernize. Although this theory would have made sense in times of industrialization, in this commentary we question its applicability to today's society. In doing so, we follow the line of argument developed by Vauclair et al. (2014), showing that increased modernization in fact leads to higher social status of older people, and aim to extend the argument beyond the availability of economic resources and employment.

The roots of modernization theory in ageism are traced back to Cowgill and Holmes' (1972, pp. 8-9) statement that "the status of the aged in the community is inversely proportional to the degree of modernization of the society" (e.g., Ayalon, 2013; Löckenhoff et al., 2009;
Vauclair et al., 2014). The authors develop a series of arguments for why this might be the case. The status of older individuals would decrease as societies go through periods of social change, they argue; as mobility and urbanization increase; as agriculture becomes less important as an economic activity decreasing the status connected to owning land acquired throughout life; as the extended family gives way to the nuclear family as the bedrock of society; and as ceremonialism decreases and literacy increases, challenging the status of older people as the bearers of wisdom and knowledge on how things should be done. Moreover, they contend that with the introduction of retirement, the welfare state took away the productive and reproductive roles of older people in society making them essentially obsolete and therefore reducing their social status, particularly in Western society where individuals' status would mainly be dependent on their productive capacity. 


\section{A critique of Modernization Theory}

One can certainly ask to what extend their argument applies equally to older men and women, sparking questions of intersectionality and gendered life courses. However, the main point of critique in this commentary is that Cowgill and Holmes (1972) did not address the issue of ageism: their argument was about the status of older individuals in society. Given that ageism can encompass both positive and negative views of older people, high status does not mean absence of ageism, just as much as losing high status does not necessarily mean increased ageism. Since positive and negative age stereotypes often coincide-for instance, older people are often described as warm but incompetent (Durante et al., 2013)-assigning higher status to older people in society may actually coincide with higher levels of ageist stereotypes. Indeed, some evidence suggests that people from East Asia, where older people traditionally have had a higher status in society, have shown to hold more negative stereotypes about older people (North \& Fiske, 2015). Therefore, instead of increased ageism, the disappearance of the higher status of older people in society may in fact be a symptom of individualization and people being judged for who they are rather than for the age group they belong to. Using an explicit measure of ageism, Ayalon (2013) finds that older people are typically viewed more positively than younger people across Europe, though that this preferential view of older over younger people vanishes as the level of secularization increases. In addition, the finding by North and Fiske (2015) that there is less ageism in more individualized countries, points in that direction.

Moreover, macro-sociological theorists have been describing a transformation of the process of modernization since the 1970s. While some argue that we have transitioned to a new era of post-modernity, others rather see it as a continuation of modernity and describe the new situation as 'new', 'second' or 'liquid' modernity (e.g., Bauman, 2000). The characteristics on which Cowgill and Holmes (1972) built their modernization theory have been fundamentally changed. Particularly the structure of the labor market and welfare policies have radically altered since, suggesting that the modernization argument might not add up anymore nowadays. This holds true particularly for the interdependence of industrialization, institutionalization of the life course and ageism.

The relationship between industrialization and ageism has repeatedly been studied. There are two lines of argument regarding this relationship. Hushbeck (1989) and McDonald (2013) focus on management practices and type of work in their analyses of industrialization and ageism. In this account, the introduction of scientific management reduced the need for skills meaning that older workers lose their competitive advantage of experience, while at the same time it valued the speed at which one could perform repetitive actions. Wear and tear resulting from physical labor strenuous to the body due to constant repetition and over-burdening of specific parts of the body meant that older workers could not follow the pace, and therefore had to be gotten rid of. Not only did industry since give way to services as the main sector of employment and did the emergence of the knowledge economy lead to a re-valuation of knowledge and skills, management has changed substantially as well, with the top-down approach of scientific management being replaced with an integrated management at the level of the shop floor (Storey, 1992), and a stronger focus on employee autonomy and job control to reduce mental and physical strain of employees (Karasek \& Theorell, 1990).

An alternative line of reasoning concerns age segregation due to the institutionalization of the life course in industrial society, as discussed by Dannefer and Feldman (2017). With the extension of the welfare state, the life course was divided in phases: some speak of the tri-partition of the life course in education, work, and pension (Kohli, 1978). Particularly the introduction of old age security has segregated old age from work, reducing intergenerational contact-contact being an important element in reducing ageism (e.g., Fasbender \& Wang, 2017)-and confirming and consolidating stereotypes of older individuals as less productive (Hagestad \& Uhlenberg, 2005). This process was exacerbated by the introduction of early retirement schemes meant to let older workers 'make space' in the labor market for younger people who were believed to be more productive. However, since the turn of the millennium there has been a policy shift towards delaying retirement and re-integration older people into the labor market (Hess, König, \& Hofäcker, 2016). The shrinking population on active age, potential of skill shortages paired with widespread concerns regarding the sustainability of welfare systems have led to an increased share of older workers in the labor market (Naegele, De Tavernier, \& Hess, 2018). Thus, the transition from work to retirement is becoming more fluid, amplified by the credo of Active Ageing in Europe that not only demands older workers to be active, but preferably also productive and engaged in the labor force (Walker, 2002). As a result, the border between the work and retirement phases of the life course fades, rolling back age segregation and improving intergenerational contact carrying the potential to reduce ageism. This argument is supported by the finding that a high labor market participation of older people is correlated with a high social status of older people (Vauclair et al., 2014). Since the shift towards active ageing in the discursive basis of ageing policy, the welfare state not only protects older people from ageism through the reduction of poverty among older generations (Durante et al., 2013; Vauclair et al., 2014), but also by making them (potential) active contributors to society.

\section{Conclusion}

In conclusion, there are a number of reasons to argue that the modernization hypothesis of ageism may not 
be congruent with recent socio-economic developments. The argument developed by Cowgill and Holmes (1972) concerned social status of older individuals, not ageism. Being fundamentally different in nature, high social status of older people could well have coincided with high levels of ageism. Increased individualization has the potential to reduce both simultaneously, as both social status of an age group and stereotyping fundamentally rely on treating an individual as part of the social group he or she belongs to, rather than as an individual. Moreover, the exclusion of older individuals from paid work induced by industrialization has recently been counteracted by developments in the labor market and social policy. Based on these arguments, we call for a new research agenda evaluating the relationship between modernization and ageism since the 1970s. It is time for a critical re-assessment of the modernization hypothesis, and for the development of an alternative narrative on the relationship between modernization and how older individuals are perceived, valued and treated in the 21st Century.

\section{Acknowledgments}

This commentary is an outcome of COST Action IS1402 "Ageism-A Multi-national, Interdisciplinary Perspective" (www.notoageism.com).

\section{Conflict of Interests}

The authors declare no conflict of interests.

\section{References}

Ayalon, L. (2013). Feelings towards older vs. younger adults: Results from the European Social Survey. Educational Gerontology, 39(12), 888-901.

Bauman, Z. (2000). Liquid modernity. Cambridge: Polity.

Cowgill, D. O., \& Holmes, L. (Eds.). (1972). Aging and modernization. New York, NY: Appleton-Century-Crofts.

Dannefer, D., \& Feldman, K. (2017). Age integration, age segregation, and Generation X: Life-course perspectives. Generations, 41(3), 20-26.

Durante, F., Fiske, S. T., Kervyn, N., Cuddy, A. J. C., Akande, A., Adetoun, B. E., . . . Storari, C. C. (2013). Nations' income inequality predicts ambivalence in stereotype content: How societies mind the gap. British Journal of Social Psychology, 52(4), 726-746.

Fasbender, U., \& Wang, M. (2017). Intergenerational con- tact and hiring decisions about older workers. Journal of Managerial Psychology, 32(3), 210-224.

Hagestad, G. O., \& Uhlenberg, P. (2005). Social separation of old and young: A root of ageism. Journal of Social Issues, 61(2), 343-360.

Hess, M., König, S., \& Hofäcker, D. (2016). Retirement transitions under changing institutional conditions: Towards increasing inequalities? Comparing evidence from 13 countries. In D. Hofäcker, M. Hess, \& S. König (Eds.), Delaying retirement: Progress and challenges of active ageing in Europe, the United States and Japan (pp. 363-378). Basingstoke: Palgrave Macmillan.

Hushbeck, J. C. (1989). Old and obsolete: Age discrimination and the American worker, 1860-1920. New York, NY: Garland.

Karasek, R., \& Theorell, T. (1990). Healthy work: Stress, productivity, and the reconstruction of working life. New York, NY: Basic Books.

Kohli, M. (1978). Soziologie des Lebenslaufs. Soziologische Texte. [Sociology of the life-course: Sociological Texts]. Darmstadt: Luchterhand.

Löckenhoff, C. E., De Fruyt, F., Terracciano, A., McCrae, R. R., De Bolle, M., Costa, P. T., . . Yik, M. (2009). Perceptions of aging across 26 cultures and their culture-level associates. Psychology and Aging, 24(4), 941-954.

McDonald, L. (2013). The evolution of retirement as systematic ageism. In P. Brownell \& J. J. Kelly (Eds.), Ageism and mistreatment of older workers: Current reality, future solutions (pp. 69-90). Dordrecht: Springer.

Naegele, L., De Tavernier, W., \& Hess, M. (2018). Work environment and the origin of ageism. In L. Ayalon \& C. Tesch-Römer (Eds.), Contemporary perspectives on ageism (pp. 73-90). Cham: Springer.

North, M. S., \& Fiske, S. T. (2015). Modern attitudes toward older adults in the aging world: A crosscultural meta-analysis. Psychological Bulletin, 141(5), 993-1021.

Storey, J. (1992). Developments in the management of human resources. Oxford: Blackwell.

Vauclair, C. M., Marques, S., Lima, M. L., Bratt, C., Swift, H. J., \& Abrams, D., (2014). Subjective social status of older people across countries: The role of modernization and employment. Journals of Gerontology, Series B: Psychological Sciences and Social Sciences, 70(4), 650-660.

Walker, A. C. (2002). A strategy for active ageing. International Social Security Review, 55(1), 121-139.

\section{About the Authors}

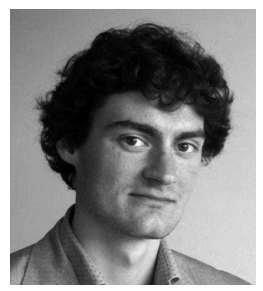

Wouter De Tavernier is a Postdoc Researcher at the Center for Social and Cultural Psychology, KU Leuven (Belgium). His research interests include employment of older workers, retirement, pensions and ageism. Before, he worked as a researcher at the Centre for Comparative Welfare Studies, Aalborg University (Denmark) where he also obtained his PhD, and at the Center for Sociological Research, KU Leuven. 


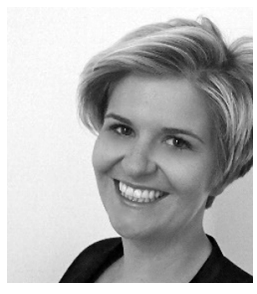

Laura Naegele is a Post-Doctoral Researcher at the Institute for Gerontology, Department of Ageing and Work at the University of Vechta, Germany. Her research topics include ageism in the labour market, ageing workforces and age management/competence management, with a focus on small and medium-sized enterprises (SMEs). Previously, she worked for the Bertelsmann Foundation out of their offices in Gütersloh (Germany) and Brussels (Belgium).

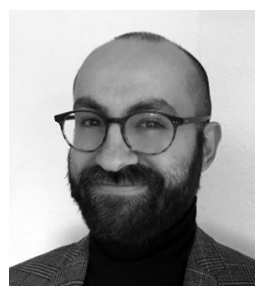

Moritz Hess is a Postdoc Researcher at the Research Centre on Inequality and Social Policy, University of Bremen (Germany). His research foci are older workers, retirement, ageism and comparative welfare state research. Before he worked at the Institute of Gerontology at TU Dortmund and the Mannheim Centre for European Social Research. 